\title{
Management of penetrating cardiac injury in a tertiary hospital in Northeast India
}

\author{
S Thokchom C. ${ }^{1}$, Laitonjam C. ${ }^{2 *}$, Nongmaithem M. ${ }^{3}$, C Arambam N. ${ }^{4}$ \\ DOI: https://doi.org/10.17511/ijmrr.2020.i01.07
}

\footnotetext{
${ }^{1}$ Chito S Thokchom, Associate Professor (CTVS), Department of Surgery, Regional Institute of Medical Sciences, Imphal, Manipur, India.

2* Chinglensana Laitonjam, Assistant Professor, Department of Surgery, Regional Institute of Medical Sciences, Imphal, Manipur, India.

3 Mackson Nongmaithem, Senior Resident, Department of Surgery, Regional Institute of Medical Sciences, Imphal, Manipur, India.

${ }^{4}$ Nejoobala C Arambam, Postgraduate trainee, Department of Surgery, Regional Institute of Medical Sciences, Imphal, Manipur, India.
}

Background: Penetrating cardiac injuries are rare and considered the most lethal of all trauma patients. Managing cardiac injuries is a great challenge for the trauma surgeons and the outcome of the treatment of such critical condition depends on the mechanism of injury, haemodynamic status of the patients at the time of presentation, heart chamber involved and other associated injuries. Materials and Methods: This is a prospective observational study of consecutive six patients with penetrating cardiac injuries from January 2015 to December 2019 treated in Regional Institute of Medical Sciences, Imphal, India. eFAST and CT scan of the chest were the main imaging methods used for diagnosis. All patients underwent tube thoracostomy for associated haemothorax in the emergency ward. Results: All the patients had penetrating cardiac injuries due to stabbing. Five $(63.3 \%)$ patients presented with features of cardiac tamponade or with severe hypotension (systolic BP less than $80 \mathrm{mmHg}$ ) and one $(16.7 \%$ ) patient who was haemodynamically stable at the time of presentation had developed features of cardiac tamponade after 24 hours. Four patients had undergone emergency left anterolateral thoracotomy, one patient had undergone median sternotomy, and one patient underwent left anterolateral thoracotomy on the second day after admission. Conclusion: A high index of suspicion for cardiac trauma is extremely important in patients presented with penetrating thoracic injuries or upper abdominal injuries. Computed tomography of the chest can show the haemopericardium giving detailed information of associated pulmonary injury and hemothorax. Prompt diagnosis and early surgical intervention play a vital role to save these critically injured patients.

Keywords: Penetrating cardiac injury, Thoracotomy, Median sternotomy, Haemopericardium, Haemothorax.

Corresponding Author

Chinglensana Laitonjam, Assistant Professor, Department of Surgery, Regional Institute of Medical Sciences, Imphal, Manipur, India.

Email: chinglensana@rediffmail.com
How to Cite this Article

To Browse

Thokchom CS, Laitonjam C, Nongmaithem M, Arambam NC. Management of penetrating cardiac injury in a tertiary hospital in Northeast India. Int J Med Res Rev. 2020;8(1):45-50.

Available From

https://ijmrr.medresearch.in/index.php/ijmrr/article/ view/1130

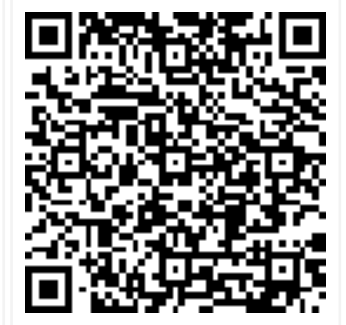

Manuscript Received 2019-12-30

Conflict of Interest No
Review Round 1 2020-01-10

Funding

$\mathrm{Nil}$
Review Round 2 2020-01-16

Ethical Approval Yes
Review Round 3

Plagiarism X-checker $7 \%$
Accepted 2020-01-20

() 2020 by Chito S Thokchom, Chinglensana Laitonjam, Mackson Nongmaithem, Nejoobala C Arambam and Published by Siddharth Health Research and Social Welfare Society. This is an Open Access article licensed under a Creative Commons Attribution 4.0 International License https://creativecommons.org/licenses/by/4.0/ unported [CC BY 4.0]. 


\section{Introduction}

A penetrating cardiac injury is among the most lethal of all injuries and its management is a great challenge for the treating team. "A wound in the heart is mortal" Hippocrates said two thousand years ago [1]. In a review of 1198 cases of penetrating cardiac injuries, only $6 \%$ of the patients arrive at the hospital alive [2]. The mechanism of cardiac injuries is of extreme importance in deciding the mode of surgical intervention. The method of assault has changed from knives and ice picks to more lethal low-velocity handguns. With the widespread use of rapid medical transportation systems, many of the victims who would have been declared dead at the scene are reaching the trauma centres in urban areas "lifeless" or in extremis. High-velocity wounds to the heart usually result in immediate exsanguinations. Mortality after penetrating cardiac wounds can be due to cardiac tamponade, exsanguination, coronary artery laceration, valvular disturbances, disruption of conduction pathways, or other associated lethal injuries such as mediastinal major vascular injury. Both early diagnosis and prompt management are of paramount importance for salvaging such patients.

Small pericardial and myocardial wounds with tamponade may be treated by pericardiocentesis with varying success rate. On the other hand, larger wounds of pericardium and myocardium caused by bullets should be managed by immediate thoracotomy and cardiorrhaphy. Direct visualization of pericardial fluid aids in the diagnosis of cardiac injury and can be accomplished through open or laparoscopic subxyphoid pericardiocentesis or exploration [3]. Subxyphoid pericardiocentesis has the advantage of being both diagnostic and therapeutic but is associated with false positives due to secondary injury to the myocardium or coronary artery. Subxyphoid or transdiaphragmatic pericardial window may be indicated if the FAST is equivocal or negative in the presence of significant hemothorax or if unexplained hypotension is present in the trauma patient undergoing exploratory laparotomy [4].

Recently, with improvement in ambulance service and rapid transport of injured patients to hospital have resulted in an increasing number of patients with penetrating cardiac injuries reach the hospital trauma centre $[5,6,7]$. Although trauma care has improved and the number of deaths from
Penetrating cardiac injuries has declined, it remains significantly high $[8,9,10]$. A high index of suspicion for cardiac trauma is required in all cases of penetrating thoracic and upper abdominal trauma. So, prompt, early diagnosis and immediate surgical intervention is crucial in the management of such cases.

This is an observational study to analyse the mechanism of cardiac injuries, management and its outcome.

\section{Materials and Methods}

\section{Study design: Hospital-based prospective observational study}

Study period: From January 2015 to December 2019

IEC approval: The RIMS Ethical Clearance Committee approved this study.

Sample size: Six patients

Inclusion criteria: All patients with penetrating cardiac injuries presented in the Emergency ward of Regional Institute of Medical Sciences were included.

Exclusion criteria: All patients with penetrating cardiac injuries or chest injuries who were dead on arrival were excluded.

Imaging methods used: All patients with penetrating cardiac injuries were initially managed in the emergency ward as per ATLS protocol. eFAST and $\mathrm{CT}$ scan of the chest were the main imaging methods used for diagnosis.

Surgical procedures: All the patients presented with associated haemothorax and intercostal drainage was done in all the patients during the initial management. Tube thoracostomy, thoracotomy and median sternotomy were the surgical procedures performed.

\section{Results}

All the six patients were male with a mean age of 29 years, the youngest being 17 years and the oldest being 51 years old. All the patients had penetrating cardiac injuries due to stabbing. Five patients had stab injury on the left side of the chest and one patient had multiple stabs or puncture wounds on the anterior aspect of the chest (Figure 1) and is caused by multipronged spear used for fishing (Figure 2). 


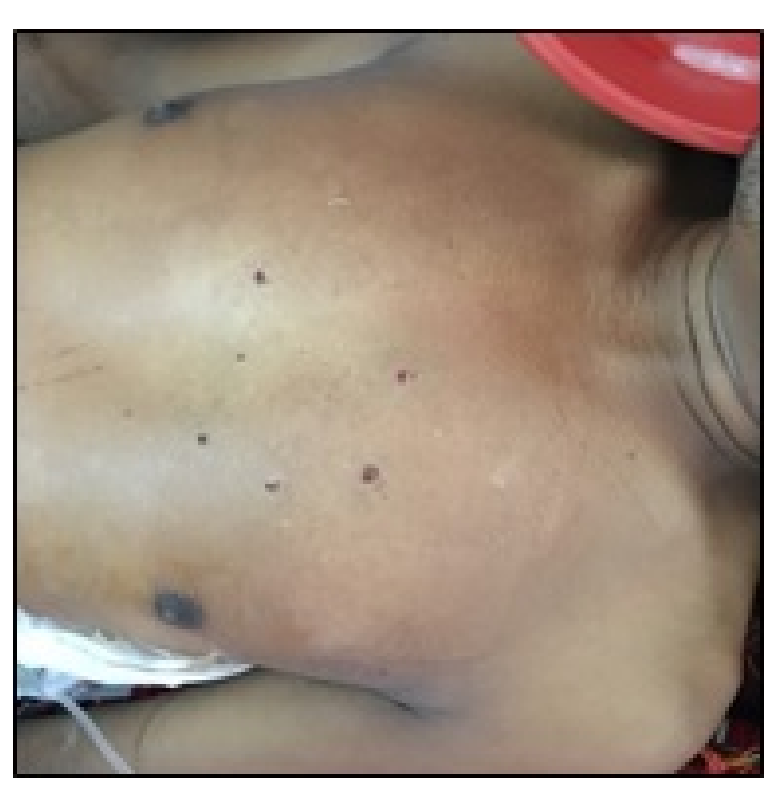

Fig-1: Precordial wounds.

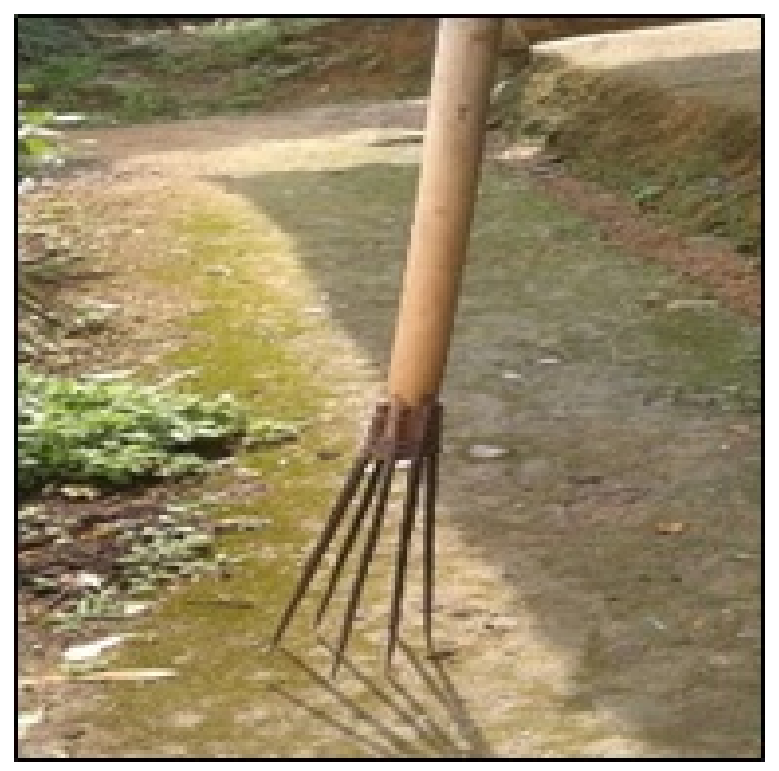

Fig-2: Multipronged spear.

Five $(63.3 \%)$ patients presented with features of cardiac tamponade or with severe hypotension (systolic BP less than $80 \mathrm{mmHg}$ ) and one (16.7\%) patient who was haemodynamically stable at the time of presentation had developed features of cardiac tamponade after 24 hours. Clinical presentation at the time of arrival is shown in Table 1.

Table-1: Clinical presentation on arrival.

\begin{tabular}{|l|l|l|l|}
\hline $\begin{array}{c}\text { Age of the } \\
\text { patient (in } \\
\text { years) }\end{array}$ & $\begin{array}{c}\text { Mechanism } \\
\text { of injury }\end{array}$ & $\begin{array}{l}\text { Site of } \\
\text { injury }\end{array}$ & \multicolumn{1}{|c|}{ Clinical presentation } \\
\hline 17 & Stab injury & $\begin{array}{l}\text { Anterior } \\
\text { chest }\end{array}$ & $\begin{array}{l}\text { Respiratory distress, severe } \\
\text { hypotension, tachycardia, bilateral } \\
\text { haemothorax, haemopericardium }\end{array}$ \\
\hline
\end{tabular}

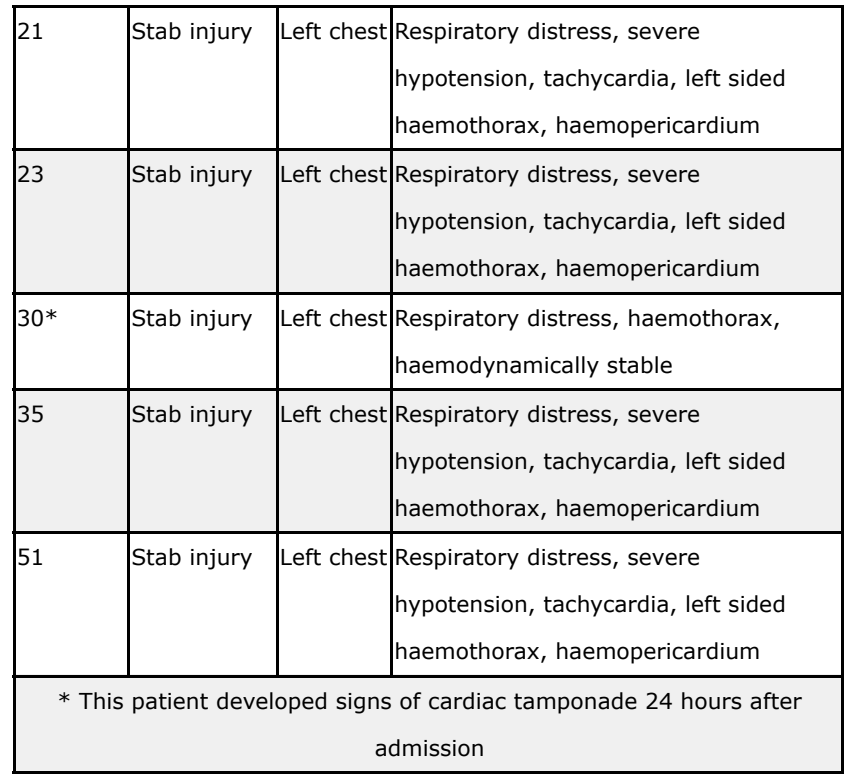

All the patients had haemothorax on the left side except in one patient who had bilateral haemothorax (Figure 3). All the patients had undergone tube thoracostomy in the emergency ward.

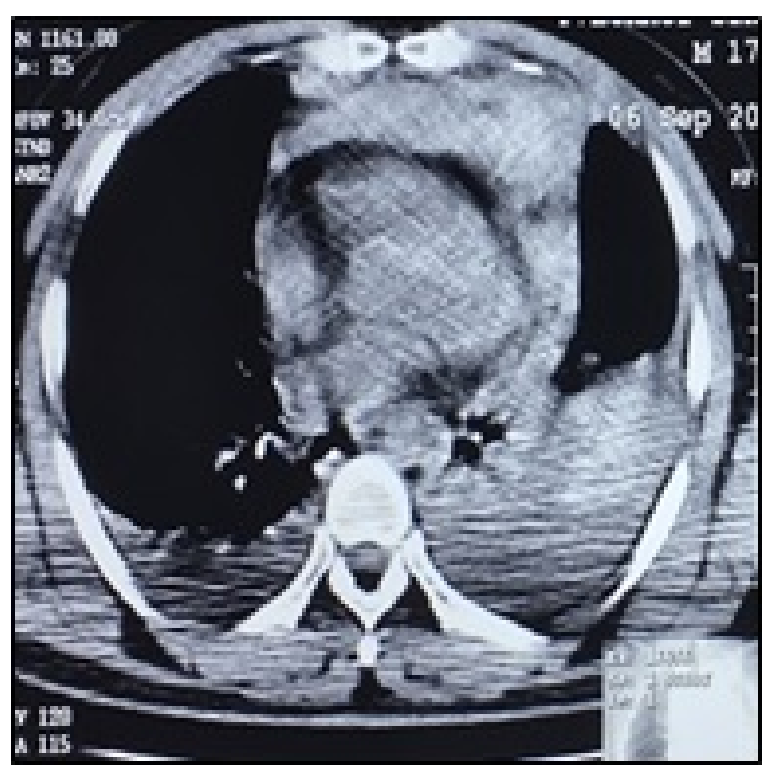

Fig-3: CT scan showing haemopericardium and bilateral haemothorax.

Four patients had undergone emergency left anterolateral thoracotomy and one patient had undergone median sternotomy. Another patient underwent left anterolateral thoracotomy on the second day after admission. Injuries encountered during operation is shown in Table 2. Three (50\%) patients had right ventricular injury and another three $(50 \%)$ patients had only pericardial injury. One patient who developed signs of cardiac tamponade 24 hours after admission had clotted haemopericardium. One patient had associated lung parenchymal injury. 
Table-2: Injuries encountered during surgery.

\begin{tabular}{|l|l|}
\hline \multicolumn{1}{|c|}{ Injuries encountered } & No. of patients \\
\hline Pericardial injury only & 1 \\
\hline Pericardial and lung injury & 1 \\
\hline Pericardial injury with left internal mammary artery injury & 1 \\
\hline Right ventricular injury & 3 \\
\hline
\end{tabular}

For pericardial injuries, pericardial bleed was controlled with electrocautery and a pericardial window was made both above and below the left phrenic nerve (Figure 4). Right ventricular injuries was repaired with 4-0 prolene and pericardial windows were made both above and below the left phrenic nerve. Right ventricular injuries were repaired without using cardiopulmonary bypass.

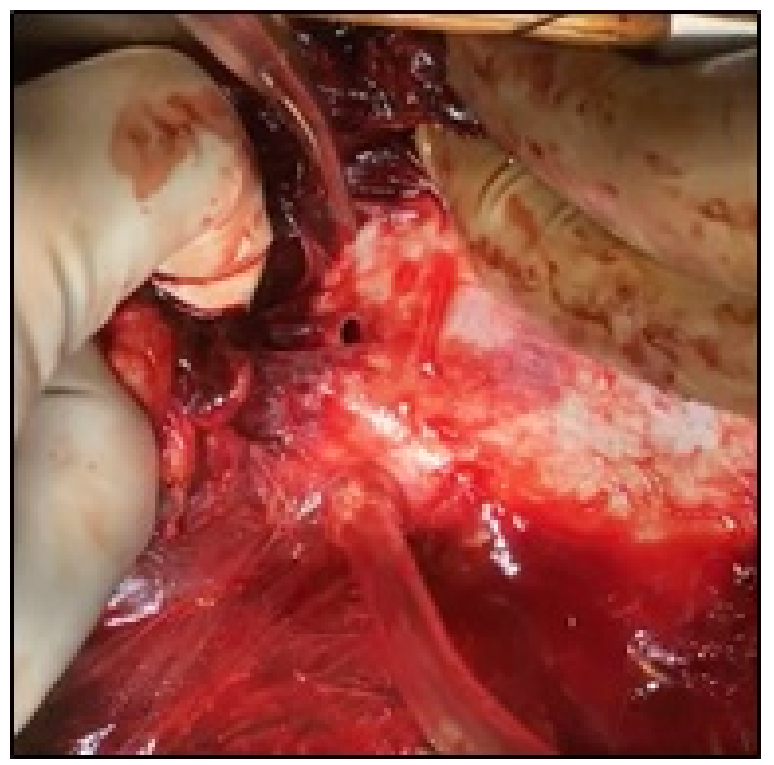

Fig-4: Pericardial injury.

All the patients had uneventful postoperative period and were discharged on the 5th to 7th postoperative day with an average length of hospital of 6 days.

\section{Discussion}

Patients with penetrating cardiac injuries arriving at the hospital alive are rare and is extremely challenging to manage. They are one of the leading causes of death in urban trauma, accounting for a high rate of prehospital death and in-hospital mortality. Most patients who sustain cardiac injuries die before reaching the hospital, and almost twothirds of patients with penetrating cardiac injuries have no vital signs upon arrival to the hospital. Although many cardiac injuries are obvious on presentation, such as a patient is a hemodynamically unstable condition with a
Penetrating injury in proximity to the heart, a diagnostic evaluation is necessary for other patients that are in stable condition and may have an occult cardiac injury. The mechanism of injury clearly influences survival. In general, these injuries are one of two types: stab or gunshot wounds. The patient's physiologic condition at the time of presentation significantly affects the outcome. The clinical features of a patient with a penetrating cardiac injury depend on the degree of pericardial tamponade and the amount of blood loss.

Over a period of last 5 years, only six patients with such critical injuries were observed. Most of the literature on penetrating cardiac injuries reported that the victims were predominantly male and the majority were due to stab wound $[11,12]$. In our series also, all the patients with penetrating cardiac injuries were male and all patients had stab wounds. While any penetrating injury to the thorax may be associated with a cardiac trauma, those within the "cardiac box" defined as inferior to the clavicles, superior to the costal margin and medial to the midclavicular line, are the most worrisome. Although some authors advocated to suspect cardiac laceration with a precordial wound, [13] the opinion from current study was that all trauma surgeons should have a high index of suspicion for cardiac injuries in patients with penetrating thoracic injuries, especially on the left side and the anterior aspect of the chest or precordial region and upper abdominal injuries. In our series, five (63.3\%) patients had a stab wound on the left side of the chest and one $(16.7 \%)$ patient had multiple stab wound on the precordium.

EFAST is a rapid real-time bedside imaging method with very high sensitivity (more than 97\%) in detection of pericardial fluid noninvasively; however it is operator dependent and suboptimal in presence of pneumopericardium, subcutaneous emphysema and large body habitus [14]. CT scan of the chest has very high sensitivity and specificity in identifying hemopericardium in stable patients with trauma [15]. In the current series, eFAST was performed in all the patients and followed by CT scan of the chest. CT scan was more relied on for the diagnosis of cardiac injury as the eFAST was done by Residents and was operator dependent. Demonstration of pneumopericardium and/or haemopericardium and haemothorax following penetrating chest injuries is suggestive pericardial rupture and is generally considered an indication for surgery. 
All penetrating cardiac injuries have the potential for mortality, and it is not clear that the particular area of the heart that is wounded carries a worse prognosis. The right ventricle composes the majority of the anterior surface of the heart and is most vulnerable to penetrating injuries. The left atrium is the least likely injured cardiac chamber because of its small size and posterior location. In $50 \%$ of our patients the right ventricle was injured. In most of the series $[16,17]$ it is that the right ventricle is most commonly injured in penetrating cardiac injury, with right ventricular injuries having the best prognosis. The probable reason might be that the right ventricle is relatively low pressure, yet with a muscular wall that can lead to effective containment of free haemorrhage. Penetrating cardiac injuries due to gunshot wounds carry a higher mortality than other penetrating injuries like stab wounds to the heart and most of the literature reported survival rates up to 5 -fold higher for stab wounds compared with gunshot wounds $[18,19]$. Penetrating cardiac injury due to gunshot wounds is more common in Western countries whereas in developing countries like India penetrating cardiac injury from stabbing is more common [20]. These differences may also influence the results of the reported series.

The surgical approach could be fundamental and the primary step to control the bleeding, median sternotomy approach gives an effective and extensive vision of heart, great vessels, to other structures in the mediastinum and to both pleural cavities. Whereas, left anterolateral thoracotomy provides rapid access to the right and left ventricles and to the pulmonary artery. Although some authors [21] debated median sternotomy or anterolateral thoracotomy approach for penetrating cardiac injuries, the authors are of the opinion that surgical approach to the penetrating cardiac injuries should depend on the time taken to reach the hospital, pre-hospital management, site of the wound, probable trajectory of the weapon and the heart chambers involved. Five $(63.3 \%)$ of our patients were approached through a left anterolateral thoracotomy and one $(16.7 \%)$ patient through a median sternotomy. Right ventricular bleeding can be temporary control by the placement of a Foley catheter or by digital control. Use of skin staples has also been reported to achieve temporary control of bleeding from right ventricular injury [22]. In the current case, three patients had right ventricular injuries and that digital control was used to decrease the bleeding, so as to facilitate defin -itive repair. The incidence and natural history of posttraumatic cardiac sequelae are not well established. The incidence of delayed sequelae of cardiac injuries varies widely in different series depending on the patient criteria used for further investigation and the methods used for imaging. Reported complications include atrial and ventricular septal defects, valvular incompetence, vascularcardiac fistulas, ventricular aneurysms, conduction abnormalities, ventricular dysfunction, dilatation or hypertrophy, intramural thrombus, endocarditis, and pericarditis [23].

The limitation of this study is the smaller number of patients.

\section{Conclusion}

Right ventricular injury is more commonly injured in patients with penetrating cardiac injuries due to stabbing. Prompt diagnosis and early surgical intervention play a vital role to save these critically injured patients.

\section{What does the study add to the existing knowledge}

A high index of suspicion for cardiac trauma is extremely important in patients presented with any penetrating thoracic injuries or upper abdominal injuries. FAST and computed tomography of the chest can show the haemopericardium giving detailed information of associated pulmonary injury and haemothorax.

\section{Author's contribution}

Dr. Chito S Thokchom: Concept, study design Dr. Chinglensana Laitonjam: Data analysis Dr. Mackson Nongmaithem: Manuscript writing Dr. Nejoobala C Arambam: Manuscript review Dr. Hirina D. Khagokpam: Proof correction

\section{Reference}

01. William A Nolen. "A short history of heart surgery". American Heritage. 1983;34:5.

[Crossref]

02. Campbell NC, Thomson SR, Muckart DJ, Meumann CM, Van Middelkoop I, Botha JB. Review of 1198 cases of penetrating cardiac trauma. Br J Surg. 1997;84(12)1737-1740.

doi: [Article] [Crossref] 
03. Smith CA, Galante JM, Pierce JL, Scherer LA. Laparoscopic transdiaphragmatic pericardial window getting to the heart of the matter. J Am Coll Surg. 2011;213(6)736-742.

doi: [Article] [Crossref]

04. Andrade-Alegre R. Penetrating cardiac injury from a wooden knitting needle. J Emerg Med. 2012;43(4)719. doi: [Article] [Crossref]

05. Szentpetery S, Lower RR. Changing concepts in the treatment of penetrating cardiac injuries. J Trauma. 1977;(6)457-461. doi: [Article] [Crossref]

06. Ivatury RR, Shah PM, Ito K, Ramirez-Schon G, Suarez F, Rohman M. Emergency room thoracotomy for the resuscitation of patients with "fatal" penetrating injuries of the heart. Ann Thorac Surg. 1981;32(4):377-385. doi: [Article] [Crossref]

07. Flynn TC, Ward RE, Miller PW. Emergency room thoracotomy. Ann Emerg Med. 1982;11(8)413416. doi: [Article] [Crossref]

08. Baker CC, Thomas AN, Trunkey DD. The role of emergency room thoracotomy in trauma. J Trauma. $1980 ; 20(10) 848-855$.

doi: [Article] [Crossref]

09. Bodai BI, Smith JP, Ward RE, O'Neill MB, Auborg $R$. Emergency thoracotomy in the management of trauma- a review. JAMA. 1983;249(14)18911896.

doi: [Article] [Crossref]

10. Breaux EP, Dupont JB Jr, Albert HM, Bryant LR, Schechter FG. Cardiac tamponade following penetrating mediastinal injuries- im- proved survival with early pericardiocentesis. J Trauma. 1979;19(6)461-466.

doi: [Article] [Crossref]

11. Isaza-Restrepo A, Bolívar-Sáenz DJ, TarazonaLara M, Tovar JR. Penetrating cardiac traumaanalysis of 240 cases from a hospital in Bogota, Colombia. World J Emerg Surg. 2017;12;26. doi: [Article] [Crossref]

12. Ezzine SB, Bouassida M, Benali M, Ghannouchi M, Chebbi F, Sassi $S$, et al. Management of penetrating cardiac injuries in the Department of surgery, Mohamed Thahar Maamouri Hospital, Tunisia- report of 19 cases. Pan African Med J. $2012 ; 11 ; 54$.

[Crossref]
13. Aksoyek A, Tutun U, Babarglu S, Parlar I. Penetrating cardiac injuries. Turk J Trauma Emerg Surg. 2007;13(2)135-141. [Crossref]

14. Adams A, Fotiadis N, Chin JY, Sapsford W, Brohi K. A pictorial review of traumatic pericardial injuries. Insights Imaging. 2012;3(4)307-311. doi: [Article] [Crossref]

15. Nagy KK, Gilkey SH, Roberts RR, Fildes JJ, Barrett J. Computed tomography screens stable patients at risk for penetrating cardiac injury. Acad Emerg Med. 1996;3(11)1024-1027. doi: [Article] [Crossref]

16. Siemens R, Polk HC, Jr Gray LA Jr, Fulton RL. Indications for Thoracotomy Following Penetrating Thoracic Injury. J Trauma. 1977;17(7)493-500. doi: [Article] [Crossref]

17. Szentpetery S, Lower, RR. Changing Concepts in the Treatment of Penetrating Cardiac Injuries. J Trauma. 1977;17(6)457-461.

doi: [Article] [Crossref]

18. Asensio JA, Berne JD, Demetriades D, Chan L, Murray J, Falabella $A$, et al. One hundred five penetrating cardiac injuries- a 2- year prospective evaluation. J Trauma. 1998;44(6)1073-1082.

doi: [Article] [Crossref]

19. Degiannis E, Loogna $P$, Doll D, Bonanno F, Bowley DM, Smith MD. Penetrating cardiac injuries- recent experience in South Africa. World J Surg. 2006;30(7)1258-1264. doi: [Article] [Crossref]

20. Kang N, Hsee L, Rizoli S, Alison P. Penetrating cardiac injury- overcoming the limits set by nature. Injury. 2009;40(9)919-927. doi: [Article] [Crossref]

21. Embrey R. Cardiac trauma. Thorac Surg Clin. 2007;17(1)87-93. doi: [Article] [Crossref]

22. O'Connor J, Ditillo M, Scalea T. Penetrating cardiac injury. J R Army Med Corps. 2009;155(3)185-190. doi: [Article] [Crossref]

23. Symbas PN, Gott JP. Delayed sequelae of thoracic trauma. Surg Clin North Am. 1989;69(1)135-142. doi: [Article] [Crossref] 